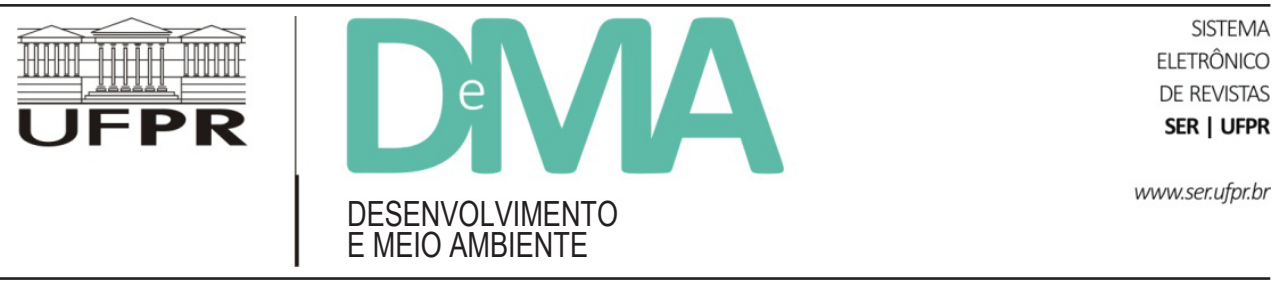

\title{
Levantamento e representatividade das Unidades de Conservação instituídas no Estado de Santa Catarina, Brasil
}

\section{Survey and Representativeness of Protected Areas Established in the State of Santa Catarina, Brazil}

\author{
Larissa MARTINS ${ }^{1}$, Rosemeri Carvalho MARENZI ${ }^{1}$, Amanda de LIMA ${ }^{1 *}$ \\ ${ }^{1}$ Universidade do Vale do Itajaí (UNIVALI), Itajaí, SC, Brasil. \\ *E-mail de contato: 1_martinsbio@yahoo.com.br
}

Artigo recebido em 24 de junho de 2014, versão final aceita em 8 de dezembro de 2014.

RESUMO: $\quad$ O sistema de Unidades de Conservação (UCs) constitui-se em uma das mais importantes políticas públicas de proteção da biodiversidade. Dessa forma, este estudo teve o intuito de levantar as UCs criadas nas três esferas governamentais no estado de Santa Catarina. Para isso, foram realizadas consultas à legislação e sites oficiais dos órgãos ambientais pertinentes; aos técnicos da Fundação do Meio Ambiente de Santa Catarina (FATMA) e a bibliografias disponíveis. Verificou-se que Santa Catarina possui $16 \mathrm{UCs}$ federais e $10 \mathrm{UCs}$ estaduais, sendo ainda prevista a instituição de duas UCs estaduais pela FATMA. Em relação às RPPNs, Santa Catarina possui 56 unidades federais e quatro estaduais, duplicando seu número a cada cinco anos desde a década de 1990. Porém, no que tange as UCs municipais, existem 163 áreas protegidas, muitas das quais não são reconhecidas como categorias de UCs e não implantadas efetivamente (65 UCs enquadradas e 98 não enquadradas no Sistema Nacional de Unidades de Conservação). Isso indica uma grande fragilidade no que se refere à gestão ambiental municipal e à proteção da biodiversidade local.

Palavras-chave: Unidades de Conservação em Santa Catarina; Sistema Nacional de Unidades de Conservação; áreas protegidas; proteção da biodiversidade.

ABSTRACT: Protected Areas (PAs) constitute one of the most important public policies for the protection of biodiversity. Thus, the purpose of this study is to assess the PAs created by the three governmental levels, in spheres of the State of Santa Catarina. To this end, we researched the legislation and official websites of relevant environmental bodies, interviewed technicians from the Environmental Foundation of Santa Catarina (FATMA), and used available bibliographies. Santa Catarina has 16 Federal and 10 State PAs. Besides, FATMA is expected to create two other PAs in that state. As far as Private Natural Reserves (RPPNs) are concerned, Santa Catarina has 56 federal and four state unitss. This number has doubled every five years since 1990. However, regarding municipalities, there are 163 municipal protected areas created by only $22.5 \%$ of local governments. Many of which are not recognized as PAs, and were not properly implemented (65 PAs were included in the national 
PA system, while 98 were not). This indicates a great fragility in relation to local municipal environmental management and biodiversity protection.

Keywords: protected areas in Santa Catarina; National Protected Area System; protected areas; biodiversity protection.

\section{Introdução}

O Estado de Santa Catarina está dentro do Bioma Mata Atlântica, constituído originalmente por diversas formações vegetais (Florestas: Ombrófila Densa, Ombrófila Mista, Estacional Semidecidual, Estacional Decidual, Ombrófila Aberta e Estepes) e ecossistemas costeiros associados, entre os quais mangues, restingas e banhados. Estes ecossistemas associados também podem ser reconhecidos em termos de políticas públicas como pertencentes ao Bioma Marinho Costeiro.

Hoje os remanescentes do Bioma Mata Atlântica estão reduzidos de sua cobertura original, encontrando-se em diversos estágios de sucessão de vegetação (MMA, 2013a). De acordo com a Fundação SOS Mata Atlântica e o Instituto Nacional de pesquisas Espaciais (SOS MA-INPE, 2011), Santa Catarina possui um remanescente de $23,04 \%$ deste Bioma, dos quais 22,10\% representam florestas, $0,82 \%$ restingas e $0,12 \%$ mangues.

Apesar de reduzida e fragmentada, estima-se que na Mata Atlântica exista cerca de $35 \%$ das espécies vegetais existentes no Brasil, incluindo diversas espécies endêmicas e ameaçadas de extinção. Tal riqueza é maior que a de alguns continentes, sendo uma região altamente prioritária para a conservação da biodiversidade mundial (MMA, 2013a). Por esse motivo, ela é considerada um Hotspot mundial, ou seja, uma das áreas mais ricas em biodiversidade e mais ameaçadas do planeta. É também decretada pela UNESCO (Organização das Nações Unidas para a Educação, a Ciência e a Cultura) Reserva da Biosfera $^{1}$ e na Constituição Federal de 1988, Patrimônio Nacional $^{2}$ (SOS MATA ATLÂNTICA, 2013). Muitos esforços têm sido lançados para a conservação desses Biomas, sejam eles governamentais ou advindos da sociedade civil e do setor privado. Uma das mais importantes ferramentas de conservação da biodiversidade, foco desse estudo, são as Unidades de Conservação (UCs). Estas são áreas protegidas destinadas à conservação da natureza e ao uso sustentável dos recursos naturais (IBAMA; WWF-BRASIL, 2007). Espaços com características naturais relevantes, cujo objetivo é assegurar amostras representativas e ecologicamente viáveis de populações, habitats e ecossistemas do território nacional e das águas jurisdicionais, salvaguardando o patrimônio biológico existente (MMA, 2014a).

Segundo o Sistema Nacional de Unidades de Conservação (SNUC), instituído pela Lei Federal n 9.985 de 2000, as 12 categorias de unidades de conservação são divididas em dois grandes grupos: as unidades de Proteção Integral e as unidades de Uso Sustentável. As unidades de Proteção Integral visam preservar a natureza, sendo permitido apenas o uso indireto dos seus recursos naturais (Brasil, 2000). Caracterizam-se por possuírem ecossistemas que necessitam de maiores cuidados devido sua fragilidade e particularidades (MMA, 2014a). Já as unidades de Uso Sustentável têm como objetivo compatibilizar a conservação da natureza com o uso sustentável de parte dos seus recursos naturais (Brasil, 2000).

Poucos trabalhos foram realizados com o intuito de levantar e/ou diagnosticar a situação de UCs catarinenses (Zaú et al., 1998; Marenzi, et al., 2005; Vitali \& Uhlig, 2010). No estudo realizado por Marenzi et al. (2005), além do levantamento das unidades de conservação das três esferas administrativas localizadas no estado de

\footnotetext{
1 Reserva da Biosfera “é um modelo, adotado internacionalmente, de gestão integrada, participativa e sustentável dos recursos naturais, com os objetivos básicos de preservação da diversidade biológica, o desenvolvimento de atividades de pesquisa, o monitoramento ambiental, a educação ambiental, o desenvolvimento sustentável e a melhoria da qualidade de vida das populações" (Brasil, 2000, art. 41), sendo constituída por uma ou várias áreas-núcleo, zonas de amortecimento e zonas de transição.

2 "A Floresta Amazônica brasileira, a Mata Atlântica, a Serra do Mar, o Pantanal Mato-Grossense e a Zona Costeira são patrimônio nacional, e sua utilização far-se-á, na forma da lei, dentro de condições que assegurem a preservação do meio ambiente, inclusive uso dos recursos naturais" (Brasil, 1988, § $4^{\circ}$, inciso VII).
} 
Santa Catarina, os autores realizaram um diagnóstico sobre a situação legal e gestacional dessas UCs, levando em consideração infraestrutura (recursos físicos e humanos), planejamento de uso, ferramentas gestacionais como Plano de Manejo e Conselho Gestor, dentre outros. Neste estudo os gestores das UCs identificaram como principais problemas a ausência de Plano de Manejo e quando existente, a falta de aplicação destes. O estudo de Zaú et al. (1998), além de listar UCs das três esferas governamentais e áreas indígenas, indica a criação de novas unidades de conservação levando em consideração a conectividade com áreas protegidas já existentes. Já o trabalho realizado por Vitali \& Uhlig (2010) deu ênfase apenas às UCs estaduais, descrevendo e analisando cada unidade na intenção de compreender a importância e os aspectos motivacionais de criação, os processos de implantação e a contribuição dessas áreas protegidas para a conservação dos ecossistemas catarinenses.

Assim, dentro desse contexto, este estudo teve por objetivo o levantamento das unidades de conservação catarinenses nas três esferas governamentais, bem como de áreas protegidas municipais públicas e não enquadradas no Sistema Nacional de Unidades de Conservação (SNUC), uma vez que este sistema reconhece apenas 12 categorias de unidades de conservação, às quais: cinco categorias de Unidades de Proteção Integral (Estação Ecológica, Reserva Biológica, Parque Nacional, Monumento Natural, Refúgio da Vida Silvestre) e sete Unidades de Uso Sustentável (Área de Proteção Ambiental, Área de Relevante Interesse Ecológico, Floresta Nacional, Reserva Extrativista, Reserva de Fauna, Reserva de Desenvolvimento Sustentável, Reserva Particular do Patrimônio Natural). Portanto, quando a denominação da UC não se refere a nenhuma destas categorias, esta foi considerada neste trabalho como "não enquadrada". A partir desse levantamento, foi possível uma discussão a respeito da situação atual do modelo implantado no estado, analisando a representatividade dos dois Biomas existentes no território catarinense, bem como a gestão pública ambiental por meio de iniciativas em nível municipal, estadual e federal. A realização desse estudo teve como principal finalidade a reunião de informações sobre as unidades de conservação existentes no estado de Santa Catarina, além de poder, de alguma forma, nortear ações subsidiando a gestão pública ambiental catarinense e possíveis tomadas de decisão.

\section{Metodologia}

A partir da necessidade da reunião de informações das unidades de conservação e áreas públicas de proteção ambiental existente no estado de Santa Catarina, realizou-se pesquisa para a obtenção de dados por meio de documentos e sites oficiais das prefeituras e dos órgãos ambientais como Fundação do Meio Ambiente de Santa Catarina - FATMA (órgão público ambiental estadual de Santa Catarina), Instituto Chico Mendes de Conservação da Biodiversidade (ICMBio) e Ministério do Meio Ambiente (MMA), assim como por meio de contato com técnicos da FATMA.

No intuído de realizar uma discussão a respeito da situação da conservação ambiental no estado, considerando a representatividade dos Biomas nas UCs e a gestão pública ambiental, foi realizada consulta à legislação em sites oficiais do governo estadual, federal e municipal, a bibliografias disponíveis em bibliotecas e na internet, como livros, periódicos, publicações oficiais do governo federal, estadual e municipal e sites de Organizações Governamentais e Não Governamentais.

Posterior à busca de dados houve uma sistematização das informações encontradas por meio de confecção de tabelas e gráficos utilizando como recurso o programa Microsoft Office Excel 2010.

\section{Resultados e discussão}

\subsection{Unidades de Conservação federais em Santa Catarina}

O Estado de Santa Catarina possui ao todo 16 unidades de conservação federais, que abrangem no total uma área de 341.088,69 hectares. Dessas 16 unidades de conservação, oito pertencem ao grupo Proteção Integral e oito ao grupo Uso Sustentável. Das unidades de Proteção Integral, duas são Estações Ecológicas, uma é Reserva Ecológica e cinco são Parques Nacionais. Já no grupo Uso Sustentável encontram-se duas Áreas de Proteção Ambiental, uma Área de Relevante Interesse Ecológico, uma Reserva Extrativista e quatro Florestas Nacionais (Tabela 1). 
TABELA 1 - Bioma, instrumento legal de criação, área (ha) e municípios abrangidos pelas Unidades de Conservação federais instituídas no estado de Santa Catarina.

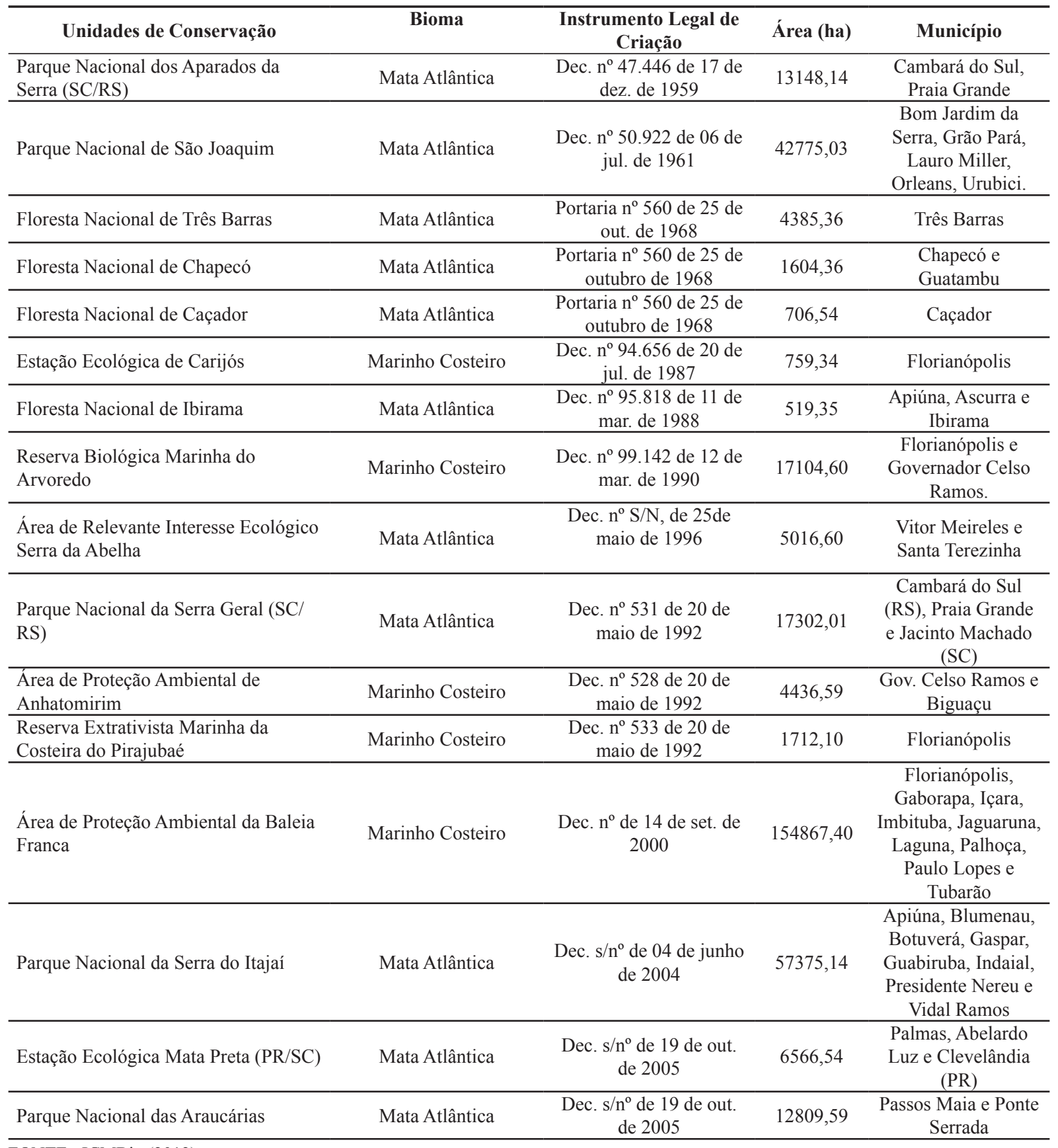

FONTE: ICMBio (2012) 
No que se refere ao ambiente protegido pelas unidades de conservação, 69\% das unidades de conservação federais do estado de Santa Catarina protegem ecossistemas da Mata Atlântica e 31\% (Cinco UCs) protegem ambientes marinhos costeiros. Isso demostra que a zona costeira e marinha catarinense é menor representada no montante de áreas federais protegidas no estado, apesar de suas características ambientais costeiras singulares. O estado de Santa Catarina possui características ambientais particulares, dentre elas o encontro das águas quentes da Corrente do Brasil com as águas frias da Corrente das Malvinas e o limite austral de manguezais em todo o Oceano Atlântico, caracterizando a alta biodiversidade marinha e costeira no estado (Souza Junior et al., s.d.). Segundo Prates et al. (2012), foi apenas a partir da década de 80 que governos e opinião pública foram alertados por pesquisadores e ambientalistas mundiais sobre a degradação de ambientes costeiros e marinhos, visto que a preocupação era maior com a proteção de ecossistemas terrestres pelo fato de os impactos sobre esses ambientes serem mais facilmente observáveis que em ecossistemas costeiros e marinhos.

O número de unidades de conservação federais em áreas de ambientes marinhos costeiros em Santa Catarina reflete uma situação encontrada também em todo o Brasil. As unidades de conservação neste país ocupam $1,5 \%$ do território marinho em contraposição aos $16,6 \%$ do território continental brasileiro (MMA, 2014b). Em nível global, das mais de cinco mil áreas protegidas existentes no mundo, apenas 1,3 mil incluem ambientes marinho e costeiros. Diante disso, em 2004, durante a Sétima Conferência das Partes (COP 7) da Convenção sobre Diversidade Biológica (CDB), os países participantes aprovaram o Programa de Trabalho sobre Áreas Protegidas (Decisão VII/28), que teve como objetivo geral, “[...] o estabelecimento e manutenção, até 2010, para áreas terrestres, e até 2012, para áreas marinhas, de sistemas nacionais e regionais de áreas protegidas abrangentes [...]" (Prates et al., 2012, p. 9). Em 2010, a $10^{\text {a }}$ Conferência dos Países Signatários da CDB, aprovou, em seu Plano Estratégico 2011-2020, a meta de conservar pelo menos $10 \%$ das zonas costeiras e marinhas em áreas protegidas, que devem ser geridas com eficácia e equidade por meio de sistemas ecologi- camente representativos. Apesar disso, o Panorama da Conservação dos Ecossistemas Costeiros e Marinhos no Brasil, de 2012, realizado pelo Ministério do Meio Ambiente, demonstra que "[...] embora haja poucos ecossistemas costeiros sub-representados no SNUC, o bioma marinho constitui a grande lacuna do sistema, demandando medidas urgentes visando o planejamento de sua conservação" (Prates et al., 2012, p. 5).

Dessa forma, apesar dos acordos assinados pelo país, em 10 anos (2002 a 2012), nenhuma unidade de conservação dessa natureza foi criada no estado de Santa Catarina (Tabela 1). No entanto, esforços por parte do governo federal têm sido lançados para a conservação das zonas costeiras no estado de Santa Catarina, especialmente considerando o desenvolvimento do Projeto Orla nos municípios de Itajaí, Navegantes, Bombinhas, Itapema, Porto Belo, Balneário Camboriú e Florianópolis (MMA, 2014c). Atualmente, o ICMBio apresenta quatro Bases Avançadas Multifuncionais atuando em Santa Catarina: o Centro Nacional de Pesquisa para Conservação das Aves Silvestres - CEMAVE, o Centro Nacional de Pesquisa e Conservação de Mamíferos Aquáticos CMA, o Centro Nacional de Pesquisa e Conservação da Sociobiodiversidade Associada a Povos e Comunidades Tradicionais - CNPT e o Centro Nacional de Pesquisa e Conservação de Tartarugas Marinhas - TAMAR. Ainda, em 2011, foi criado, por meio da Portaria nº 32, o Núcleo de Gestão Integrada das Unidades Marinho-Costeiras de Santa Catarina, composta por todas as unidades de conservação e centros de pesquisa do ICMBio atuantes da zona costeira do estado de Santa Catarina, tendo como objetivo uma efetiva conservação da biodiversidade nessa região (Souza Junior et al., s.d.).

\subsection{Unidades de Conservação estaduais em Santa Catarina}

O estado de Santa Catarina possui 10 unidades de conservação que abrangem, no total, uma área aproximada de 111.019 hectares. Todas as UCs estaduais são pertencentes ao grupo de Proteção Integral. Dessas unidades de uso indireto, sete são Parques Estaduais e três são Reservas Biológicas (Tabela 2). 
TABELA 2 - Bioma, instrumento legal de criação, área (ha) e municípios abrangidos pelas Unidades de Conservação estaduais instituídas pelo estado de Santa Catarina.

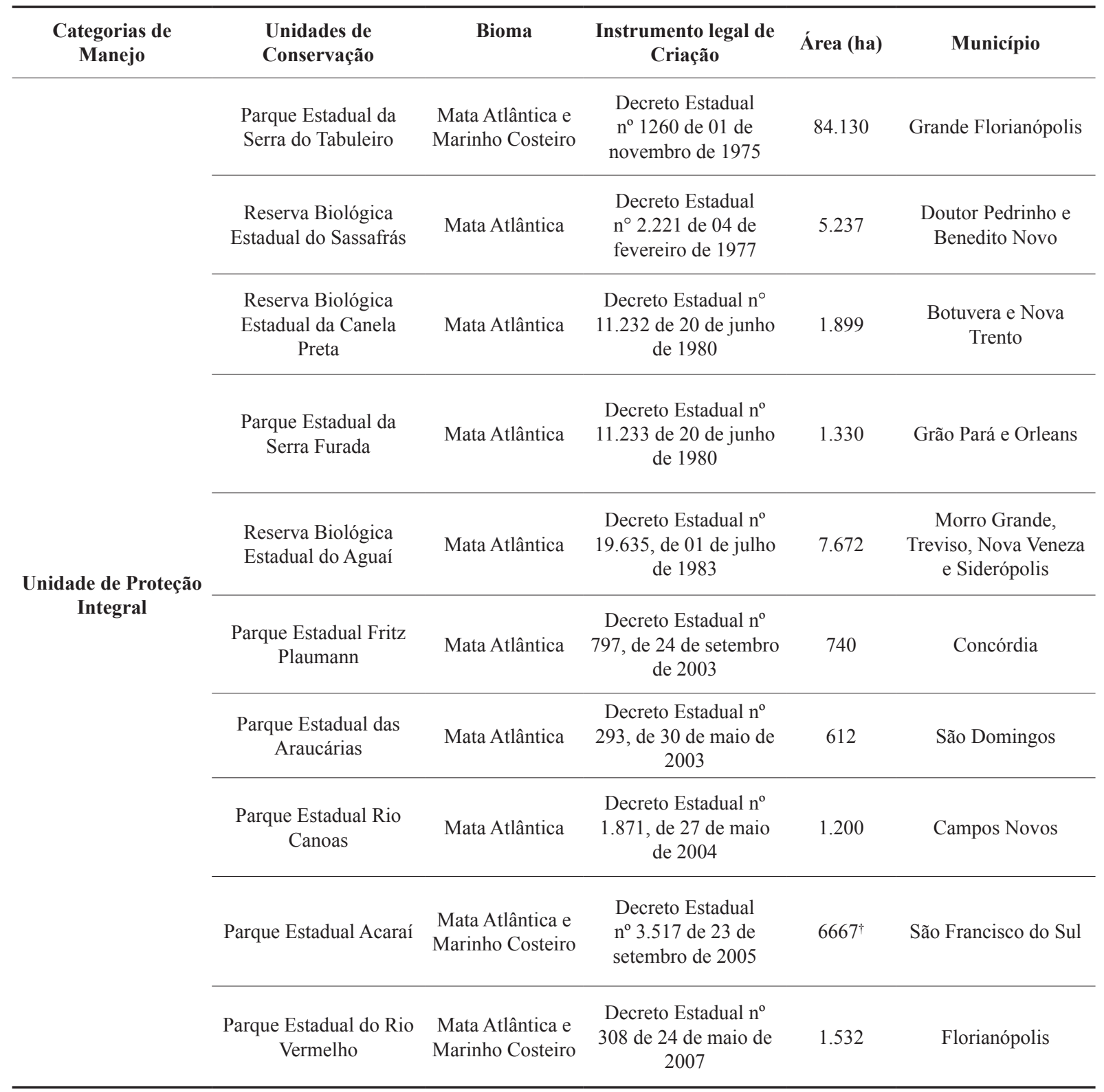

FONTE: Adaptado de FATMA (2014a).

$\dagger$ Área, em hectares, obtida a partir do Decreto de criação da unidade de conservação, encontrado em FATMA (2014a). 
Além das UCs levantadas, está em processo de criação o Refúgio Estadual da Vida Silvestre Raulino, cujo objetivo será a proteção da espécie Raulinoa echinata, planta ameaçada de extinção e endêmica de parte do rio Itajaí, localizado entre os municípios de Lontras e Indaial (FATMA, 2013). Ainda, a Fundação do Meio Ambiente de Santa Catarina (FATMA) está desenvolvendo projetos para a criação do Parque Estadual "Serra do Rio do Rastro" (nome provisório), na região dos municípios de Bom Jardim da Serra, Lauro Müller e Treviso (FATMA, informação pessoal).

Assim como na esfera federal, verificou-se também a pouca representatividade dos ambientes costeiros e marinhos no conjunto de unidades de conservação estaduais. De 10 unidades, apenas três (30\%) possuem em seus limites ecossistemas marinhos e costeiros, representados pelo Parque Estadual da Serra do Tabuleiro, pelo Parque Estadual Acaraí e pelo Parque Estadual do Rio Vermelho. Ainda assim, a gestão deste último Parque passou do município ao estado.

\subsection{Reservas Particulares do Patrimônio Natural (RPPNS) no estado de Santa Catarina}

Segundo o Decreto Federal n ${ }^{\circ} 1.922$ de 5 de junho de 1996 (Brasil, 1996), também conhecida por Lei da RPPN, Reserva Particular do Patrimônio Natural é:

área de domínio privado a ser especialmente protegida, por iniciativa de seu proprietário, mediante reconhecimento do Poder Público, por ser considerada de relevante importância pela sua biodiversidade, ou pelo seu aspecto paisagístico, ou ainda por suas características ambientais que justifiquem ações de recuperação $\left(\right.$ Art. $1^{\circ}$ ).

As RPPNs, embora possuam áreas pequenas na sua maioria, contribuem para o Sistema Nacional de Unidades de Conservação, ao desempenhar funções de complementaridade das UCs públicas, protegendo remanescentes que servem de corredores ecológicos em um mosaico de áreas protegidas, bem como de trampolins ecológicos e de zona de amortecimento no entorno dessas UCs públicas (Mesquita \& Vieira, 2004). As RPPNs assumem grande importância, haja vista as atuais dificuldades econômicas e políticas para a criação de UCs públicas, além de desonerar o Poder Público de gastos com indenizações e gestão das áreas (Ojidos et al., 2008).

De acordo com o Instituto Chico Mendes de Conservação da Biodiversidade (ICMBio), Santa Catarina é o quarto estado com o maior número de RPPNs Federais instituídas (56 RPPNs) (Tabela 3), perdendo apenas para os estados de Bahia (94 RPPNs), Minas Gerais (88 RPPNs) e Rio de Janeiro (65 RPPNs). Em termos de áreas totais de conservação por meio dessa categoria de unidade de conservação, Santa Catarina é o sexto estado com maior área, com 28.805,21 hectares, ficando atrás somente dos estados de Mato Grosso, Mato Grosso do Sul, Bahia, Minas Gerais e Goiás (ICMBio, 2012a).

Percebe-se que no estado de Santa Catarina, do ano de 1990 ao ano de 2012, de acordo com a Figura 1, progressivamente tem aumentado o número de unidades de conservação particulares federais instituídas, praticamente duplicando o número a cada cinco anos. Acredita-se que esse aumento deva-se à institucionalização de políticas públicas de incentivo ao proprietário particular (pessoa física) como forma de compensação às práticas conservacionistas dos proprietários, assim como a existência de fundos para o financiamento da manutenção da RPPN. Além disso, várias organizações ambientalistas possuem programas de apoio a essas unidades de conservação. Vale ressaltar que existe hoje um novo paradoxo da sociedade no que se refere à concepção do desenvolvimento econômico sustentável e de conservação da natureza, propiciando o aumento de iniciativas da sociedade civil para a proteção do patrimônio natural. Ainda, muitas empresas privadas têm utilizado a criação de RPPNs como forma de compensação ambiental e como melhoria na reputação da empresa (Mesquita \& Vieira, 2004), mesmo que o SNUC estabeleça a exigência de investimentos em UCs de proteção integral.

Pode-se constatar ainda que, em média, as RPPNs catarinenses são pequenas, em torno de 490 hectares. E dentre os municípios catarinenses, aqueles que possuem um maior número de RPPNs, demonstrando uma maior iniciativa da comunidade local, é Itaiópolis, com oito RPPNs, seguido por Urubici, com sete RPPNs e por Bom Retiro, com cinco RPPNs (Tabela 3). 


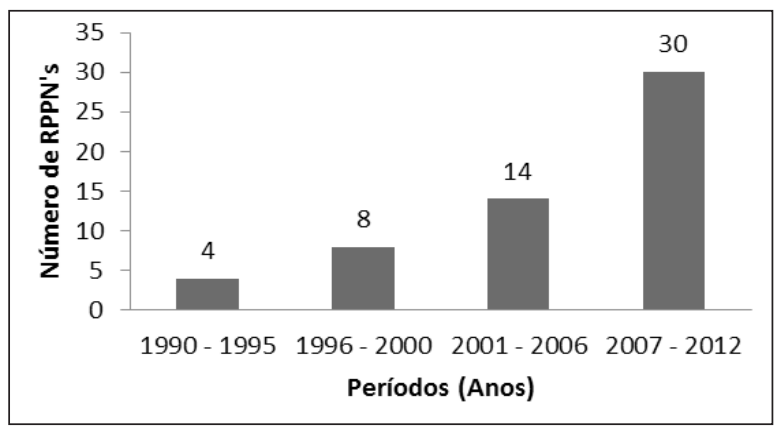

FIGURA 1 - Número de RPPNs federais criadas em Santa Catarina em quatro períodos consecutivos, desde a institucionalização dessa categoria de Unidade de Conservação, no ano de 1990. FONTE: Autores (2014).

TABELA 3 - Ano de criação, área (ha) e municípios abrangidos pelas Reservas Particulares do Patrimônio Natural (RPPNs) federais criadas no estado de Santa Catarina.

\begin{tabular}{cccc}
\hline RPPN & Ano de criação & Área (ha) & Município \\
\hline Reserva do Caraguatá III & 1990 & 1854 & Antônio Carlos \\
\hline Fazenda Palmital & 1992 & 590,6 & Itapoá \\
\hline Parque Ecológico ARTEX & 1993 & 5296,16 & Blumenau \\
\hline Reserva BugerKopf & 1993 & 82,7 & Ituporanga \\
\hline Fazenda Pousada Serra Pitoco & 1997 & 3 & Antônio Carlos \\
\hline Reserva do Caraguatá II & 1998 & 558,86 & Major Gercino \\
\hline Reserva do Caraguatá I & 1998 & 900,39 & Balneário Camboriú \\
\hline Normando Tedesco & 1999 & 3,82 & Florianópolis \\
\hline Reserva Natural Menino Deus & 1999 & 16 & Florianópolis \\
\hline Morro das Aranhas & 1999 & 44,16 & Santa Rosa de Lima \\
\hline Barra do Rio do Meio & 1999 & 10 & São Joaquim \\
\hline Fazenda Araucária & 2000 & 50 & Água Doce \\
\hline Gralha-Azul & 2001 & 49 & Brusque \\
\hline Chácara Edith & 2001 & 415,79 & Joinville \\
\hline Caetezal & 2001 & 4613,8 & Nova Trento \\
\hline Prima Luna & 2001 & 100 & São Bento do Sul \\
\hline Ano Bom & 2001 & 88 & São José \\
\hline Reserva do Patrimônio Natural do Guaxinim & 2001 & 26 & Alfredo Wagner \\
\hline Reserva Rio das Furnas & 2002 & 10 & Brusque \\
\hline Bio Estação Águas Cristalinas & 2002 & 102,96 & Corupá \\
\hline Emilio Fiorentino Battistella & 2002 & 1156,33 & São Francisco do Sul \\
\hline Morro dos Zimbros & 2002 & 45,9 & 7 \\
\hline Morro da Palha & 2002 & &
\end{tabular}


TABELA 3 - Conclusão

\begin{tabular}{|c|c|c|c|}
\hline RPPN & Ano de criação & Área (ha) & Município \\
\hline Passarim & 2004 & 226,47 & Paulo Lopes \\
\hline Capão Redondo & 2005 & 14,04 & Balneário Arroio do Silva \\
\hline Vale das Pedras & 2008 & 33,58 & Alfredo Wagner \\
\hline Curucaca 4 & 2008 & 59,46 & Bom Retiro \\
\hline Santuário Rã-Bugio I & 2008 & 1,89 & Guaramirim \\
\hline Santuário Rã-Bugio II & 2008 & 2,75 & Guaramirim \\
\hline Leão da Montanha & 2008 & 126,5 & Urubici \\
\hline Fazenda Santa Terezinha & 2009 & 60 & Água Doce \\
\hline Taipa do Rio Itajaí & 2009 & 23,12 & Itaiópolis \\
\hline Corredeiras do Rio Itajaí & 2009 & 332,92 & Itaiópolis \\
\hline Grutinha & 2009 & 5,99 & Nova Trento \\
\hline Retiro Tun & 2009 & 4,95 & Rancho Queimado \\
\hline Pedra da Águia & 2009 & 100 & Urubici \\
\hline Serra do Lucindo & 2010 & 316,05 & Bela Vista do Toldo \\
\hline Porto Franco & 2010 & 45 & Botuverá \\
\hline Taipa Rio do Couro & 2010 & 36,3 & Itaiópolis \\
\hline Raso do Mandi & 2012 & 54,34 & Itaiópolis \\
\hline Corredeiras do Rio Itajai II & 2012 & 79,05 & Itaiópolis \\
\hline Odir Zanelatto & 2012 & 212,07 & Itaiópolis \\
\hline Passarim II & 2012 & 66,7 & Paulo Lopes \\
\hline Florescer & 2012 & 155,15 & Urubici \\
\hline Portal Agua Branca & 2012 & 201,54 & Urubici \\
\hline Corvo Branco & 2012 & 13,46 & Urubici \\
\hline
\end{tabular}

FONTE: Sistema informatizado de monitoria de RPPN (ICMBio, 2012b). 
TABELA 4 - Ano de criação, área (ha) e municípios abrangidos pelas Reservas Particulares do Patrimônio Natural (RPPNs) estaduais criadas no estado de Santa Catarina.

\begin{tabular}{cccc}
\hline RPPN & $\begin{array}{c}\text { Ano de } \\
\text { criação }\end{array}$ & Área (ha) & Município \\
\hline Rio do Prata Bugio & 2011 & 15 & Anitápolis \\
\hline Reserva de Fontes e Verdes & 2012 & 130,47 & Jaraguá do Sul e Rio dos Cedros \\
\hline Pedra Branca & 2012 & 10,57 & Alfredo Wagner \\
\hline Complexo Serra da Farofa & 2014 & $4.987,15$ & Bocaina do Sul, Painel, Urupema, Urubici e Rio Rufino \\
\hline
\end{tabular}

FONTE: Fundação do Meio Ambiente (FATMA, 2014b). ${ }^{3}$

No Estado de Santa Catarina, recentemente RPPNs estaduais (RPPNEs) têm sido instituídas pelo órgão ambiental catarinense. A primeira RPPNE foi criada apenas no ano de 2011, a RPPNE Rio do Prata Bugio. Acredita-se que isso se deva ao fato da regulamentação do reconhecimento das Reservas Particulares do Patrimônio Natural Estaduais pela FATMA ter sido realizada apenas no ano de 2010, através do Decreto Estadual $n^{\circ}$ 3.755 (Santa Catarina, 2010).

\section{4. Áreas protegidas e Unidades de Conservação municipais em Santa Catarina}

\subsubsection{Unidades de Conservação municipais enquadradas no SNUC}

Apesar das áreas destinadas às unidades de conservação municipal, a maioria delas pequenas quando comparadas com as unidades de conservação federais e estaduais, possuem importante papel para o Sistema de Unidades de Conservação. Assim como as RPPNs, as UCs municipais podem permitir a conexão de unidades de conservação federais e estaduais maiores, aumentando o conjunto de áreas protegidas e funcionando como corredores ecológicos (IBGE, 2005).

No estado de Santa Catarina existem, de acordo com a tabela 5, 65 unidades de conservação municipais enquadradas no Sistema Nacional de Unidades de Conservação, possuindo, ao todo, três categorias pertencentes ao grupo Proteção Integral e duas integrantes do grupo Uso Sustentável.
Das unidades de conservação municipais, 33 são Áreas de Proteção Ambiental (APA), seis são Áreas de Relevante Interesse Ecológico (ARIE), 21 são Parques Naturais Municipais (PNM) e cinco são Reservas Biológicas (REBio). Além disso, pode-se verificar que o município que possui o maior número de unidades de conservação municipais é Blumenau (oito UCs), seguido de Criciúma e Timbó (seis UCs) e Itajaí (cinco UCs).

\subsection{2. Áreas protegidas municipais (não enquadradas no SNUC)}

No estado de Santa Catarina, conforme a tabela 6, 98 são áreas municipais destinadas à conservação dos recursos naturais não enquadradas e não reconhecidas pelo Sistema Nacional de Unidades de Conservação. Segundo a Pesquisa de informações básicas Municipais, referente ao ano 2002, essa é uma realidade encontrada não só no estado de Santa Catarina. O estudo do IBGE mostra que muitas unidades municipais dos estados brasileiros não constituíam verdadeiras unidades de conservação, visto que não atendiam à nomenclatura estabelecida pelo SNUC ou não apresentavam nomenclatura completa. O referido estudo mostra que de 1.498 áreas destinadas à conservação no país, apenas 689 UCs municipais se enquadravam no SNUC. Acredita-se que tal situação deva-se à carência de conhecimento dos gestores municipais quanto à legislação referente à criação, implantação e gestão de unidades de conservação, bem como ao fato da maioria dessas áreas terem sido criadas antes da existência do SNUC (IBGE, 2005).

\footnotetext{
3 Existem três processos de criação em andamento de RPPNs, instituídas pela esfera estadual, nas quais são: RPPNE Rio dos Pardos, RPPNE Cascatas, RPPNE Prof. Yara C. Nicoletti.
} 
TABELA 5 - Instrumento legal de criação, área (ha) e municípios abrangidos pelas Unidades de Conservação municipais do estado de Santa Catarina.

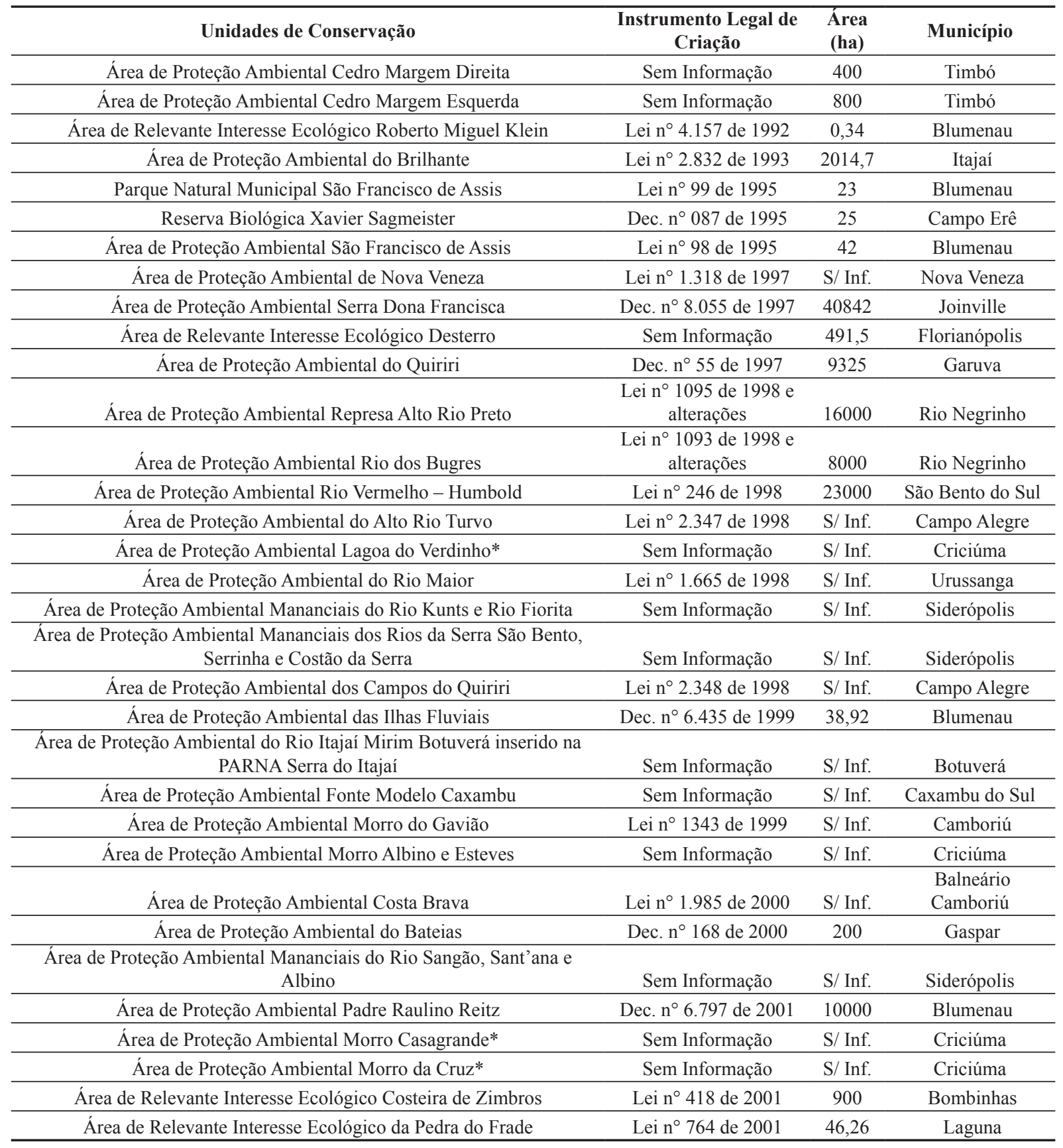

(continua) 


\begin{tabular}{|c|c|c|c|}
\hline Unidades de Conservação & $\begin{array}{c}\text { Instrumento Legal de } \\
\text { Criação }\end{array}$ & $\begin{array}{l}\text { Área } \\
\text { (ha) }\end{array}$ & Município \\
\hline Parque Natural Municipal do Vale do Rio do Peixe & Lei $n^{\circ} 2.800$ de 2002 & 285,68 & Joaçaba \\
\hline Parque Natural Municipal Broomberg & Lei $^{\circ} 5.869$ de 2002 & 6,7 & Blumenau \\
\hline Área de Relevante Interesse Ecológico do Morro do Boa Vista & Dec. $n^{\circ} 11.005$ de 2003 & 390 & Joinville \\
\hline Parque Natural Municipal Gruta de São José* & Sem Informação & S/ Inf. & São Bonifácio \\
\hline Parque Natural Municipal Rio Fortuna & Sem Informação & S/ Inf. & Timbó \\
\hline Reserva Biológica Municipal Dionísio Cerqueira & Sem Informação & 12 & Dionísio Cerqueira \\
\hline Reserva Biológica Treze Tilhas & Sem Informação & 2 & Treze Tilhas \\
\hline Área de Proteção Ambiental Municipal do Rio Ferreira & Sem Informação & S/ Inf. & Treviso \\
\hline Área de Proteção Ambiental Parque Ecológico José Milanese* & Sem Informação & S/ Inf. & Criciúma \\
\hline Área de Proteção Ambiental Parque Morro Cequinel* & Sem Informação & S/ Inf. & Criciúma \\
\hline Área de Proteção Ambiental Parque Salura* & Sem Informação & S/ Inf. & Frei Rogério \\
\hline Área de Proteção Ambiental de Içara & Lei n ${ }^{\circ} 2019$ de 2004 & S/ Inf. & Içara \\
\hline Parque Natural Municipal Araponguinhas & Sem Informação & S/ Inf. & Timbó \\
\hline Parque Natural Municipal Nascente do Garcia & Sem Informação & 5300 & Blumenau \\
\hline Parque Natural Municipal da Caieira & Dec. $\mathrm{n}^{\circ} 11.734$ de 2004 & 127,94 & Joinville \\
\hline Parque Natural Municipal João José Theodoro da Costa Neto & Lei $\mathrm{n}^{\circ} 228$ de 2005 & 234,42 & Lages \\
\hline Parque Natural Municipal Raimundo Gonçalez Malta & Lei $n^{\circ} 2.611$ de 2006 & 17,26 & $\begin{array}{l}\text { Balneário } \\
\text { Camboriú }\end{array}$ \\
\hline Parque Natural Municipal Caminho do Peabiru & Dec. $n^{\circ} 428$ de 2007 & 428,5 & Barra Velha \\
\hline Parque Natural Municipal do Atalaia & Dec. $n^{\circ} 8.107$ de 2007 & 19,508 & Itajaí \\
\hline Área de Relevante Interesse Ecológico do Salto & Dec. $n^{\circ} 8408$ de 2007 & 16 & Blumenau \\
\hline Parque Natural Municipal Cordeiros & Lei $^{\circ} 5.195$ de 2008 & 1,18 & Itajaí \\
\hline Área de Proteção Ambiental do Saco da Fazenda & Dec. $8.513 / 2008$ & 65 & Itajaí \\
\hline Parque Natural Municipal Trilha dos Bugres & Dec. $\mathrm{n}^{\circ} 44$ de 2008 & 90,9 & Imbuia \\
\hline Reserva Biológica da Praia do Rosa & Sem Informação & 5 & Imbituba \\
\hline Reserva Biológica de Irineópolis & Sem Informação & 113 & Irineópolis \\
\hline Parque Natural Municipal Carijós & Lei n 330 de 2011 & 39,76 & Itapoá \\
\hline Parque Natural Municipal Centenário & Lei $^{\circ} 1.121$ de 2011 & 18 & Piratuba \\
\hline Parque Natural Municipal Chapéu das Águas & Lei $^{\circ} 1.753$ de 2010 & 509,64 & Vidal Ramos \\
\hline Parque Natural Municipal de Navegantes & Lei $^{\circ} 117$ de 2011 & 14,712 & Navegantes \\
\hline Parque Natural Municipal Franz Dann* & Sem Informação & S/ Inf. & Timbó \\
\hline Parque Natural Municipal Freymund Germer & Lei $n^{\circ} 402$ de 2011 & 36,615 & Timbó \\
\hline Parque Natural Municipal da Ilha das Capivaras/Sibara & 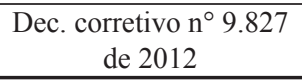 & 11,52 & Itajaí \\
\hline
\end{tabular}

FONTE: FATMA - dados não publicados (2012); FATMA (2004); Cimardi \& Gaio (2001);

*Necessita confirmação da Categoria. 
TABELA 6 - Instrumento legal, área (ha) e municípios abrangidos pelas áreas protegidas municipais do estado de Santa Catarina (não enquadradas no SNUC).

\begin{tabular}{|c|c|c|c|}
\hline Áreas Protegidas & Instrumento Legal de Criação & $\begin{array}{c}\text { Área } \\
\text { (ha) }\end{array}$ & Município \\
\hline Área de Preservação Permanente "Prainha" (a ser confirmada) & Sem Informação & S/ Inf. & Irani \\
\hline $\begin{array}{l}\text { Área de Preservação Permanente Municipal Joinville (a ser } \\
\text { confirmada) }\end{array}$ & Sem Informação & S/ Inf. & Joinville \\
\hline Área de Preservação Permanente Encostas & $\begin{array}{c}\text { Leis } \mathrm{n}^{\circ} 2193 \text { de } 1985 \text { e }^{\circ} 1851 \\
\text { de } 1982\end{array}$ & 608,4 & Florianópolis \\
\hline Área de Preservação Permanente Pontal da Daniela & Sem Informação & S/ Inf. & Florianópolis \\
\hline Área de Preservação Primeira Linha & Sem Informação & 12,48 & Criciúma \\
\hline Área Tombada da Ilha do Campeche & Sem Informação & S/ Inf. & Florianópolis \\
\hline Área Tombada da Lagoa da Chica & Dec. $\mathrm{n}^{\mathrm{o}} 135$ de 1988 & 4,6 & Florianópolis \\
\hline Área Tombada da Lagoinha Pequena & Dec. $n^{\circ} 135$ de 1988 & 27,5 & Florianópolis \\
\hline Área Tombada Dunas da Armação do Pântano do Sul & Dec. $\mathrm{n}^{\mathrm{o}} 112$ de 1985 & 5,9 & Florianópolis \\
\hline Área Tombada Dunas da Barra da Lagoa & Sem Informação & S/ Inf. & Florianópolis \\
\hline Área Tombada Dunas do Campeche & Dec. $\mathrm{n}^{\mathrm{o}} 112$ de 1985 & 121 & Florianópolis \\
\hline Área Tombada Dunas do Pântano do Sul & Dec. $\mathrm{n}^{\circ} 112$ de 1985 & 24,2 & Florianópolis \\
\hline Área Tombada Parque da Luz & Sem Informação & 3 & Florianópolis \\
\hline Área Tombada Ponta do Sambaqui & Dec. $n^{\circ} 216$ de 1985 & 1,3 & Florianópolis \\
\hline Área Tombada Região do Alto Silva (a ser confirmada) & Sem Informação & S/ Inf. & Nova Trento \\
\hline Área Tombada Restinga de Ponta das Canas & Dec. $n^{\circ} 216$ de 1985 & 21,5 & Florianópolis \\
\hline Parque Municipal da Ressacada & Dec. $n^{\circ} 2.824$ de 1982 & 130 & Itajaí \\
\hline Parque Municipal das Dunas da Lagoa da Conceição & Dec. $\mathrm{n}^{\circ} 231$ de 1988 & 515 & Florianópolis \\
\hline Parque da Luz & Sem Informação & 3,7 & Florianópolis \\
\hline Parque Municipal da Ilha do Amaral & Dec. $n^{\circ} 6.182$ de 1989 & 336 & Joinville \\
\hline Parque Ecológico de Maracajá & Não identificado & 112 & Maracajá \\
\hline Parque Ecológico do Córrego Grande & Sem Informação & 21,48 & Florianópolis \\
\hline Parque Municipal da Galheta & Lei $\mathrm{n}^{\circ} 3.455$ de 1990 & 149,3 & Florianópolis \\
\hline Parque Municipal de São Bonifácio & Lei ${ }^{\circ} 671$ de 1991 & 4,84 & São Bonifácio \\
\hline Parque Ecológico Prefeito Rolf Colin & Dec. $n^{\circ} 6.959$ de 1992 & 1630 & Joinville \\
\hline Parque Municipal da Lagoinha do Leste & Lei nº 4701 de 1992 & 780,9 & Florianópolis \\
\hline
\end{tabular}


TABELA 6 - Continuação

\begin{tabular}{|c|c|c|c|}
\hline Áreas Protegidas & Instrumento Legal de Criação & $\begin{array}{c}\text { Área } \\
\text { (ha) }\end{array}$ & Município \\
\hline Parque Ecológico Municipal de Piratuba & Sem Informação & 2 & Piratuba \\
\hline Parque Municipal do Morro do Finder & Dec. $n^{\circ} 7.056$ de 1993 & 50 & Joinville \\
\hline Parque Ecológico Rio Camboriú & Sem Informação & 17 & Balneário Camboriú \\
\hline Parque Ecológico Spitzkopf & Sem Informação & S/ Inf. & Blumenau \\
\hline Parque Florestal Bütner (a ser confirmada) & Sem Informação & S/ Inf. & Brusque \\
\hline Parque Florestal Refúgio (a ser confirmada) & Sem Informação & S/ Inf. & Gaspar \\
\hline Parque Municipal 23 de Setembro & Sem Informação & 4 & São Bento do Sul \\
\hline Parque Municipal Boa Vista & Sem Informação & 17 & Joinville \\
\hline Parque Municipal Cachoeira do Fernandes & Sem Informação & S/ Inf. & São João Batista \\
\hline Parque Municipal Cachoeira do Peroba & Não Existe & 10 & Santa Rosa do Sul \\
\hline Parque Municipal Castelo Morro dos Passarinhos & Sem Informação & 2 & Palmitos \\
\hline Parque Municipal da Canhanduba & Sem Informação & 100 & Itajaí \\
\hline Parque Municipal Morro do Macaco & Lei $n^{\circ} 113$ de 1994 & 266,82 & Bombinhas \\
\hline Parque Municipal da Galheta & Lei $n^{\circ} 97$ de 1994 & 132 & Bombinhas \\
\hline Parque Municipal do Maciço da Costeira & Lei ${ }^{\circ} 4.605$ de 1995 & 1455,87 & Florianópolis \\
\hline Parque Ecológico Municipal de Palhoça & Dec. $n^{\circ} 428$ de 1996 & 359,67 & Palhoça \\
\hline Parque Municipal Foz do Ribeirão Garcia & Lei comp. $n^{\circ} 125$ de 1996 & 1,7 & Blumenau \\
\hline Parque Municipal da Uva & Sem Informação & 1 & Videira \\
\hline Parque Municipal das Grutas de Botuverá & Lei $n^{\circ} 820$ de 1999 & 17,96 & Botuverá \\
\hline Parque Municipal das Palmeiras & Sem Informação & 5 & Chapecó \\
\hline Parque Municipal das Quedas & Sem Informação & 6 & Brusque \\
\hline Parque Municipal de Timbó & Sem Informação & 60 & Timbó \\
\hline Parque Municipal do Manguezal do Itacorubi & Dec. $n^{\circ} 1.529$ de 2002 & 187,4 & Florianópolis \\
\hline Parque Municipal Índio Condá & Sem Informação & 15 & Chapecó \\
\hline Parque Municipal Macaco Branco & Sem Informação & 3 & Itapiraga \\
\hline Parque Municipal Rio Novo Alto Corupá & Sem Informação & S/ Inf. & Corupá \\
\hline Parque Municipal Zoobotânico & Sem Informação & S/ Inf. & Joinville \\
\hline Parque Rodoviário Rio do Rastro & Sem Informação & 40 & Bom Jardim da Serra \\
\hline Parque Urbano do Morro da Cruz & Lei Mun. $n^{\circ} 6893$ de 2005 & 144,9 & Florianópolis \\
\hline Parque Municipal de Preservação Ambiental Tombo D'água & Dec. $\mathrm{n}^{\circ} 80$ de 2006 & 91,78 & Imaruí \\
\hline Reserva Ambiental Natureza Viva & Sem Informação & S/ Inf. & Blumenau \\
\hline Reserva da Rede Ferroviária (Imaruí) (a ser confirmado) & Sem Informação & S/ Inf. & Imaruí \\
\hline Reserva da Rede Ferroviária (a ser confirmada) & Sem Informação & S/ Inf. & Araquari \\
\hline Reserva Ecológica Escola Agrícola de Araquari & Sem Informação & S/ Inf. & Araquari \\
\hline Reserva Ecológica Lanchares (a ser confirmado) & Sem Informação & S/ Inf. & Rancho Queimado \\
\hline Reserva Ecológica do Bom Retiro & Sem Informação & S/ Inf. & Blumenau \\
\hline Reserva Ecológica Núcleo Tentrícola (a ser confirmada) & Sem Informação & S/ Inf. & Frei Rogério \\
\hline Reserva Ecológica Rio Turvo (a ser confirmada) & Sem Informação & S/ Inf. & Garuva \\
\hline
\end{tabular}


TABELA 6 - Conclusão

\begin{tabular}{|c|c|c|c|}
\hline Áreas Protegidas & Instrumento Legal de Criação & Área (ha) & Município \\
\hline Reserva Ecológica Videira (a ser confirmada) & Sem Informação & S/ Inf. & Treze Trilhas \\
\hline Reserva Volta Velha & Sem Informação & 1100 & Itapuá \\
\hline Terra Indígena Cachoeira dos Inácios & Sem Informação & S/ Inf. & Imaruí \\
\hline Terra Indígena de Ibirama & Sem Informação & S/ Inf. & $\begin{array}{c}\text { Victor Meireles e José } \\
\text { Boitex }\end{array}$ \\
\hline Terra Indígena Guarani do Aracai & Sem Informação & S/ Inf. & Saudades \\
\hline Terra Indígena Massiambu & Sem Informação & S/ Inf. & Palhoça \\
\hline Terra Indígena Mbguaçu & Sem Informação & S/ Inf. & Biguaçu \\
\hline Terra Indígena Pinhal & Sem Informação & S/ Inf. & Seara \\
\hline Terra Indígena Piraí & Sem Informação & S/ Inf. & Araquari \\
\hline Terra Indígena Rio dos Pardos & Sem Informação & S/ Inf. & Porto União \\
\hline Terra Indígena Tarumã/Pindoty & Sem Informação & S/ Inf. & Araquari \\
\hline Terra Indígena Toldo Cimbangue & Sem Informação & S/ Inf. & Chapecó \\
\hline Terra Indígena Toldo Cimbangue II & Sem Informação & S/ Inf. & Chapecó \\
\hline Terra Indígena Toldo Imbu & Sem Informação & S/ Inf. & Abelardo Luz \\
\hline Unidade de Conservação Ambiental Desterro & Sem Informação & S/ Inf. & Florianópolis \\
\hline Unidade de Conservação Lagoa Verdinho & Sem Informação & 38 & Criciúma \\
\hline
\end{tabular}

FONTE: FATMA - dados não publicados (2012); FATMA (2004); Cimardi \& Gaio (2001); FLORAM (2013).

Destas áreas protegidas não enquadradas no SNUC, 38 possuem as nomenclaturas Terras Indígenas, Área de Preservação Permanente, Horto Florestal, Área Tombada, e quatro possuem, em sua denominação, apenas "Unidade de Conservação" (sem categoria). O restante constitui-se de áreas protegidas municipais com uma nomenclatura inadequada, como por exemplo, Parque Municipal.

As categorias Parque Nacional e Floresta Nacional, em especial, estão especificadas no SNUC, devendo, na criação, dentro da esfera municipal, serem denominadas de Parque Natural Municipal e Floresta Municipal, respecti- vamente, de acordo com os artigos Art. 11, $\S 4^{\circ}$ e Art. 17, $\S 6^{\circ}$ (Brasil, 2000). Já as categorias Terras Indígenas, Área de Preservação Permanente, Horto Florestal e Área Tombada, apesar de não serem reconhecidas pelos SNUC como unidades de conservação, sendo apenas "figura legal" de caráter municipal e de reconhecimento do poder público, são de importância para a conservação da biodiversidade dentro dos municípios, se respeitados seus propósitos.

As Áreas Tombadas estão submetidas a um regime especial de cuidados, objetivando evitar sua descaracterização original, devendo estar inscritas no Livro do

${ }^{4}$ Apesar da categoria Estação Ecológica ser reconhecida pelo SNUC, a Estação Ecológica do Bracinho é de domínio da Celesc, não sendo administrada pela FATMA. 
Tombo (CECCA, 1997). Em Florianópolis, áreas de tombamento foram reconhecidas segundo o Decreto-lei municipal $\mathrm{n}^{\circ} 112$, de 31 de maio de 1985 , objetivando conservar áreas de dunas. Segundo CECCA (1997, p. 43):

[...] as áreas tombadas são um avanço em termos de dispositivo legal de preservação, uma vez que são criadas por legislação específica e incidem sobre uma área concreta. Em caso de serem inseridas em Área de Preservação Permanente (APP), representam um importante esforço legal, por elevarem o status de legislação genérica de preservação à legislação específica.

Já as APPs (Áreas de Preservação Permanente), segundo o Código Florestal (Brasil, 2012) constituem-se em áreas legalmente protegidas com a função de preservar recursos hídricos, a paisagem, a estabilidade geológica e a biodiversidade, facilitar o fluxo gênico de fauna e flora, proteger o solo e assegurar o bem-estar das populações humanas. Referem-se a ecossistemas como restingas, manguezais, margem de rios, nascentes, encostas e topos de morros, dentre outros. Portanto, nomenclaturas da legislação federal, não sendo categorias de UCs.

As Terras indígenas, por sua vez, são áreas asseguradas pela Constituição Federal de 1988, sendo que o Art. 231 estabelece que "são reconhecidos aos índios sua organização social, costumes, línguas, crenças e tradições, e os direitos originários sobre as terras que tradicionalmente ocupam, competindo à União demarcá-las, proteger e fazer respeitar todos os seus bens" (Brasil, 1988). Atualmente, o Ministério do Meio Ambiente está desenvolvendo ações voltadas às questões indígenas, como a implantação e desenvolvimento da Política Nacional de Gestão Ambiental e Territorial de Terras Indígenas (MMA, 2013b).

No que se refere a todas as áreas protegidas municipais, enquadradas ou não no SNUC, apenas 66 dos 293 municípios do estado de Santa Catarina possuem alguma área municipal destinada à conservação dos recursos naturais, o que corresponde a $22,5 \%$ dos municípios catarinense (Tabelas 5 e 6), demonstrando a fragilidade e as dificuldades no que tange a gestão ambiental. Esse baixo número de municípios com áreas protegidas segue uma tendência nacional, visto que apenas $7,8 \%$ dos municípios brasileiros possuem UCs municipais (IBGE, 2005).

Verifica-se que dos 66 municípios catarinenses que possuem UCs, aquele com maior número de áreas protegidas totais é Florianópolis (28 áreas protegidas), seguido por Blumenau (12 áreas protegidas), Joinville (11 áreas protegidas) e Criciúma (10 áreas protegidas), conforme Tabelas 5 e 6 e Figura 2.

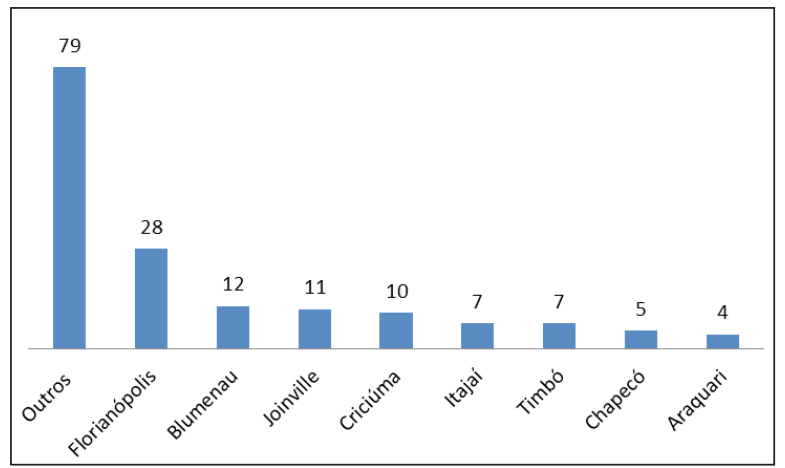

FIGURA 2 - Número de áreas protegidas municipais enquadradas ou não no SNUC, em Santa Catarina. Os "outros" representam municípios que possuem de 3 a 1 unidade de conservação em seus limites.

Os municípios com o processo de desenvolvimento socioeconômico acelerado, possuem maior representatividade em UCs, normalmente são aqueles que sofrem maior pressão antrópica, portanto, resultando em uma maior necessidade de planejamento urbano, incluindo neste áreas protegidas. Conforme Benatti (1998) a existência de áreas protegidas contribui para a preservação dos recursos naturais, pois incentiva um uso adequado desses espaços.

Além das áreas protegidas municipais não enquadradas no SNUC, vale destacar as áreas particulares certificadas pela FSC (Forest Stewardship Council). Atualmente, o Brasil possui 6,35 milhões de hectares certificados na modalidade de manejo florestal, entre áreas de florestas nativas e plantadas, e ocupa o $5^{\circ}$ lugar no ranking total do sistema FSC (Florestas Certificadas, 2014). Estas áreas são importantes, pois além de fornecerem produtos madeireiros e não madeireiros (frutos, sementes, raízes, para a extração de óleos, corantes, entre outros), contribuem significativamente para a expansão de habitats, além dos serviços ambientais que oferecem. 


\section{Conclusão}

A criação de unidades de conservação é uma das melhores alternativas para a salvaguarda de ecossistemas no Brasil. O estado de Santa Catarina possui, ao todo, 249 áreas legalmente protegidas em seu território, sendo 151 unidades de conservação reconhecidas pelo SNUC. Desse total de UCs, 16 são federais, 10 estaduais, 65 municipais, 98 áreas protegidas municipais e 60 RPPNs.

Contudo, fazem-se necessárias medidas para efetivar muitas destas UCs, especialmente quanto à problemática conceitual, pois muitas não são enquadradas no SNUC, não possuem Planos de Manejo ou aplicação desses, bem como apresentam problemas de conectividade, conforme estudos levantados. Em nível municipal, por exemplo, as áreas protegidas estão distribuídas em apenas 22,5\% dos municípios, sendo muitas delas não reconhecidas como categorias de UCs e não implantadas efetivamente. Tal fato demonstra a fragilidade da gestão ambiental nos municípios, necessitando de políticas públicas que proporcionem o fortalecimento dos sistemas municipais de unidade de conservação, pois apesar da indefinição de representação das diferentes zonas fitoecológicas protegidas por UCs, percebe-se tendência de maior deficiência de representatividade de Floresta Ombrófila Mista, Floresta Estacional Semidecidual e Estepes.

Além disso, deve-se levar em consideração, para a viabilidade das populações, a conectividade entre as unidades de conservação através da criação de corre-

\section{Referências}

Benatti, J. H. A Criação de Unidades de Conservação em Áreas de Apossamento de Populações Tradicionais Um Problema Agrário ou Ambiental? Novos Cadernos, 1(2), 46, 1998.

Brasil. Constituição da Republica Federativa do Brasil, de 5 de outubro de 1988. Brasília, DF: Senado Federal.

Brasil. Decreto Federal no 1.922, de 5 de junho de 1996. Dispõe sobre o reconhecimento das Reservas Particulares do Patrimônio Natural, e dá outras providências. Brasília: DOU de 7/6/1996. dores ecológicos. Função essa exercida pelas unidades de conservação municipais e RPPNs, que geralmente possuem pequenas áreas. Outro ponto a se considerar é a representatividade dos diferentes ecossistemas no sistema nacional e estadual de unidade de conservação. Verificou-se nas unidades de conservação estaduais e federais em Santa Catarina, que os ambientes costeiros e marinhos são menos representativos se que outros ecossistemas da Mata Atlântica. Constatação essa, que, infelizmente, reflete uma situação encontrada no Brasil.

Além das unidades de conservação criadas pelo poder público, Santa Catarina possui, no total, 60 RPPNs. Desde o ano de 1990 o número de RPPNs no estado tem duplicado a cada cinco anos. Acredita-se que esse fato deva-se as políticas públicas de incentivo à criação de RPPNs. Estas, além de contribuírem com as UCs públicas na conservação da biodiversidade, por apresentarem as funções de trampolim ecológico, corredor ecológico e zona de amortecimento, desoneram o Estado com gastos para a desapropriação de terras na criação das UCs e também na manutenção. Por isso, as RPPNs constituem-se em um grande potencial para a conservação da biodiversidade em nosso país, já que grande parte das áreas naturais localiza-se em territórios particulares.

\section{Agradecimentos}

Aos técnicos e funcionários da Fundação do Meio Ambiente de Santa Catarina (FATMA) que disponibilizaram informações para a realização da presente pesquisa.

Brasil. Lei Federal n ${ }^{\circ}$ 9.985, de 18 de julho de 2000. Institui o Sistema Nacional de Unidades de Conservação da Natureza e dá outras providências. Brasília: DOU de 19/7/2000.

Brasil. Lei Federal n 12.651, de 25 de maio de 2012. Dispõe sobre a proteção da vegetação nativa; altera as Leis nos 6.938, de 31 de agosto de 1981, 9.393, de 19 de dezembro de 1996, e 11.428, de 22 de dezembro de 2006; revoga as Leis nos 4.771, de 15 de setembro de 1965, e 7.754, de 14 de abril de 1989, e a Medida Provisória no 2.166-67, de 24 de agosto de 2001; e dá outras providências. Brasília: DOU de 25/5/2012. 
CECCA - Centro de estudos cultura e cidadania. Unidades de conservação e áreas protegidas da ilha de Santa Catarina: caracterização e legislação. Florianópolis: Insular, 1997.

Cimardi, A.; Gaio, M. F. Áreas protegidas de Santa Catarina. Florianópolis: FATMA, 2001 (Relatório).

FATMA - Fundação do Meio Ambiente. Cartograma áreas protegidas em Santa Catarina, 2004. Disponível em: <http:// www.acaprena.org.br/planodemanejo/artigos/cartograma_das areas_protegidas_em_sc.pdf $>$. Acesso em: jan. 2013.

FATMA - Fundação do Meio Ambiente. Fundação do Meio Ambiente. Disponível em: <http://www.fatma.sc.gov.br/>. Acesso em: jan. 2013.

FATMA - Fundação do Meio Ambiente. Unidades de Conservação. Disponível em: <http://www.fatma.sc.gov.br/conteudo/ unidades-de-conservacao $>$. Acesso em: nov. 2014a.

FATMA - Fundação do Meio Ambiente. RPPNs criadas/andamento. Disponível em: $<\mathrm{http}: /$ www.fatma.sc.gov.br/conteudo/ criadas-andamento $>$. Acesso em: nov. 2014b.

FLORAM - Fundação do Meio ambiente de Florianópolis. Disponível em: <http://www.pmf.sc.gov.br/entidades/floram/ index.php?pagina $=$ home\&menu=0 . Acesso em: jan. 2013.

Florestas Certificadas. Certificação Florestal. Disponível em: http://www.florestascertificadas.org.br/cf/certificacao-florestal>. Acesso em: set. 2014.

IBAMA; WWF-BRASIL. Efetividade de gestão das unidades de conservação federais do Brasil. Brasília: IBAMA, 2007.

IBGE - Instituto Brasileiro de Geografia e Estatística. Pesquisa de informações básicas municipais. Perfil dos municipios brasileiros: meio ambiente, 2002. Rio de Janeiro: 2005.

ICMBio - Instituto Chico Mendes de Conservação da Biodiversidade. Sistema informatizado de monitoria de RPPN. Disponível em: < http://sistemas.icmbio.gov.br/simrppn/ publico/>Acesso em: dez. 2012a

ICMBio - Instituto Chico Mendes de Conservação da Biodiversidade. Sistema informatizado de monitoria de RPPN. Disponível em: <http://sistemas.icmbio.gov.br/simrppn/publico/ rppn/SC/>. Acesso em: dez. 2012b

ICMBio - Instituto Chico Mendes de Conservação da Biodiversidade. Unidades de conservação federais do Brasil, 2012. Disponível em: <http://www.icmbio.gov.br/portal/comunicacao/downloads.html>. Acesso em: jan. 2013.

Marenzi, R. C.; Frigo, F.; Eccel, R.; Schimidt, A. D. Unidades de Conservação de Santa Catarina: Base Preliminar de um
Diagnóstico de Situação. In: Anais do $3^{\circ}$ Simpósio de Áreas Protegidas: repensando escalas de atuação. Pelotas: Universidade Católica de Pelotas, 2005.

Mesquita, C. A. B.; Vieira, M. C. W. (Org.). RPPN-Reserva particular do patrimônio natural da mata atlântica. São Paulo: Conselho Nacional da Reserva da Biosfera da Mata Atlântica, 2004.

MMA - Ministério do Meio Ambiente. Mata Atlântica. Disponível em: $<$ http://www.mma.gov.br/biomas/mata-atlantica $>$. Acesso em: jan. 2013a.

MMA - Ministério do Meio Ambiente. Terras indígenas. Disponível em: $<$ http://www.mma.gov.br/desenvolvimento-rural/ terras-ind\%C3\%ADgenas $>$. Acesso em: jan. $2013 \mathrm{~b}$.

MMA - Ministério do Meio Ambiente. O Sistema Nacional de Unidades de Conservação da Natureza. Disponível em: $<\mathrm{http}$ ://www.mma.gov.br/areas-protegidas/sistema-nacional-de-ucs-snuc $>$. Acesso em: abr. 2014a

MMA - Ministério do Meio Ambiente. O Sistema Nacional de Unidades de Conservação da Natureza. Disponível em: $<$ http:// www.parnanoronha.com.br/portal/images/pages/files/149_publicacao05072011052951.pdf > . Acesso em: abr. 2014b

MMA - Ministério do Meio Ambiente. Projeto Orla. Disponível em: <http://www.mma.gov.br/gestao-territorial/ gerenciamento-costeiro/projeto-orla/municipios-atendidos>. Acesso em: set. 2014c

Ojidos, F.; Rizzieri, J.; Simões, L. L. (Coord.). Reserva particular do patrimônio natural-RPPN: iniciativa cidadã para a proteção da natureza. São Paulo, 2008.

Prates, A. P. L.; Gonálves, M. A.; Rosa, M. R. Panorama da conservação dos ecossistemas costeiros e marinhos no Brasil. Brasília: MMA, 2012.

Santa Catarina. Decreto Estadual ${ }^{\circ} 3.755$, de 22 de dezembro de 2010. Dispõe sobre o reconhecimento das Reservas Particulares do Patrimônio Natural Estadual - RPPNE no âmbito do Estado de Santa Catarina. Florianópolis: DO de 22/12/2010.

SOS MA; INPE - Fundação SOS Mata Atlântica; Instituto Nacional de Pesquisas Espaciais. Atlas dos remanescentes florestais da mata atlântica: Período 2008-2010. São Paulo: 2011. Disponível em: <http://www.inpe.br/noticias/arquivos/ pdf/atlasrelatoriofinal.pdf $>$.

SOS MATA ATLÂNTICA. Mata Atlântica. Disponível em: $<$ http://www.sosma.org.br/nossa-causa/a-mata-atlantica/>. Acesso em: jan. 2013. 
Souza Junior, S.; Lopes, L. J. S.; Correia, E. C.; Macedo, H. S.; Floriani, D. C.; Silva, L. Z.; Cataneo, V. T.; Serafini, P. P.; Pretto, D. J.; Campos, A.; Rocha, M. E. C.; Ito, E. M. B.; Ferreira, I. V.; Lamberts, A.; Lima, E. P. Conservação da biodiversidade na zona costeira e marinha de Santa Catarina. ICMBio, s.d. Disponível em: <http://www.icmbio.gov. br/portal/images/Conserva $\% \mathrm{C} 3 \% \mathrm{~A} 7 \% \mathrm{C} 3 \% \mathrm{~A} 3 \mathrm{o} \% 20 \mathrm{da} \% 20$ Biodiversidade $\% 20$ na $\% 20$ Zona $\% 20$ Costeira $\% 20 \mathrm{e} \% 20$ Marinha\%20de\%20Santa\%20Catarina.pdf>
Vitali, M.; Uhlig, V. M. Unidades de Conservação de Santa Catarina. Sustentabilidade em Debate, 43-61, 2010. Disponível em: <http://periodicos.unb.br/index.php/sust/article/ viewFile/729/446>.

Zaú, A. S.; Vieira, E. G. M.; Chagas, C. S. Áreas especiais no Estado de Santa Catarina. Floresta e Ambiente, 5(1), 11-23, 1998. Disponível em: <http://www.floram.org/files/ v5n\%C3\%BAnico/v5nunicoa1.pdf $>$. 